\title{
CHALLENGES IN BUILDING ONTOLOGY FOR SHARING ECONOMY DOMAIN
}

\author{
Ummul H. Mohamad ${ }^{1 \mathrm{a}}$, Ahmad Mujahid Ubaidillah Zakaria ${ }^{2,1}$, Mohammad Nazir Ahmad ${ }^{1}$ \\ and Nor Hazila Mohd Zain ${ }^{3}$ \\ ${ }^{I}$ Institute of Visual Informatics, Universiti Kebangsaan Malaysia, 43600 Bangi, Selangor \\ ${ }^{2}$ Faculty of Business, Finance and Information Technology, MAHSA University, Jalan SP2, Bandar Saujana Putra, \\ 42610 Jenjarom, Selangor \\ ${ }^{3}$ Faculty of Business, Information and Human Sciences, Infrastructure University Kuala Lumpur, \\ 43000 Kajang, Selangor
}

\begin{abstract}
The sharing economy (SE) is one of the emerging domains in this digital era. Yet, little is known on how far or how well the ontology development has been executed for this domain. Ontology development in the SE domain is important, especially to manage the interoperability of heterogeneous systems. This paper presents the challenges in building the ontology for the SE domain. Among them are collaborative platform management issues, tackling information overload, the sustainability of the SE domain and the preference to build application ontology in SE. By understanding all these challenges, the ontology development in the SE domain can be refined to a more systematic structure.
\end{abstract}

\section{KEYWORDS}

Collaborative Consumption, Domain Ontology, Knowledge Management, Ontological Issues, Peer-To-Peer Sharing

\section{INTRODUCTION}

In contrast to the traditional business, the sharing economy (SE) can be defined through these characteristics (Matzner, Chasin, von Hoffen, Plenter, \& Becker, 2016): (i) existence of economic transactions between individuals or stakeholders, (ii) absence of any permanent ownership transfer, (iii) the interaction manner falls between sharing and trade, (iv) it involves IT-based technology and, e) it allows sharing of physical objects that are owned or accessible by one of the parties involved.

SE involves communication across multiple players such as people (users, merchants) and machines (software, program, algorithm and many more). Therefore, it can be difficult for the players to understand the meaning of concepts and terms without the presence of a common language which is understandable to players of the SE domain. This is one of the reasons why ontology is needed for the SE domain; i.e. to serve as a standard to manage commonalities. For example, having a common framework for the SE domain will help capture the heterogeneous SE data, manage the information (Khantong \& Ahmad, 2019) and allow knowledge sharing (Ahmad, Zakaria, \& Sedera, 2013) across multiple players of the SE domain.

Moreover, the SE domain mainly involves the integration of various digital platforms (e.g. IT systems). If each of the digital platforms uses different terminologies to describe the same thing, this will affect the interoperability of the supposedly integrated systems. Ontology bridges the terminology gap by providing a common knowledge for smoother integration. Additionally, the development of digital platforms in the SE domain will refer to this common knowledge.

Since everything in the SE domain happens in digital or virtual form, the information will accumulate faster and expand larger, to become more complex within a short time span. Being heavily reliant on digital mediation, SE needs optimization in terms of convenience, speed, and seamlessness of digital interactions (Sutherland \& Jarrahi, 2018). Ontology is deemed as the way to unveil the complexity of the SE domain in a more understandable manner. These reasons justify the need to have an ontology for the SE domain, simply to make the domain knowledge become more explicit. Ontology enhances the flexibility and agility of the SE domain by helping the involved players to speak and understand the same language.

\footnotetext{
${ }^{\text {a }}$ Corresponding author: ummulhanan@ukm.edu.my
} 
Gruber (1993) defined ontology as "an explicit specification of a conceptualization". In other words, ontology is a study on making information understandable in a machine-readable format within a domain of interest (Musen, 2002). Ontologies can be categorized as upper ontology, domain ontology, task ontology and application ontology. The upper ontology describes the general-purpose or flexible concepts that can be applied universally, common across all domains. Domain ontology describes the controlled vocabulary related to a specific domain specialized in the terms introduced in the upper ontology. Task ontology, on the other hand, corresponds to specialized concepts that are activity-related to carry out a particular task. Finally, application ontology is defined as the ontological concepts that depend on specific applications.

Hashemi, Khadivar, \& Shamizanjani (2018) claimed that many organizations viewed ontology-driven knowledge management as a competitive advantage or their economic survival key. Since there is yet to be any common domain ontology for SE that can systematically describe the domain knowledge for sharing economy, this research is of importance.

\section{A REVIEW OF ONTOLOGY DEVELOPMENT IN SHARING ECONOMY DOMAIN}

Initially, a total of 225 papers were identified from several major publishers such as Web of Science (apps.webofknowledge.com), Emerald Insight (https://www.emerald.com/insight/), Springer (www.springerlink.com) and IEEE (http://ieeexplore.ieee.org/Xplore). The papers included were the papers with full-text articles published after 2014. Then, papers with relevant abstracts that discussed ontology in the SE domain were selected, to obtain a manageable number of papers for narrative review. Table 1 shows the findings based on the 10 finally selected papers.

Table 1. Ontology development in SE domain

\begin{tabular}{|c|c|c|c|}
\hline No. & $\begin{array}{l}\text { Ontology } \\
\text { classification }\end{array}$ & Challenges & References \\
\hline 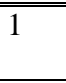 & $\begin{array}{l}\text { Application ontology } \\
(\text { sedl) }\end{array}$ & $\begin{array}{l}\text { Difficulty to find the right platform due to the availability } \\
\text { of multiple platforms in a similar domain }\end{array}$ & (von Hoffen, 2017) \\
\hline 2 & $\begin{array}{l}\text { Application ontology } \\
\text { (discover2share) }\end{array}$ & $\begin{array}{l}\text { Current ontology exists for platforms on sharing physical } \\
\text { resources only }\end{array}$ & $\begin{array}{l}\text { (von Hoffen, Matzner, } \\
\text { \& Chasin, 2015) }\end{array}$ \\
\hline 3 & $\begin{array}{l}\text { Domain ontology } \\
\text { (designer-user } \\
\text { interaction) }\end{array}$ & $\begin{array}{l}\text { No formalized ontology on designer-user interaction, } \\
\text { leading to missing knowledge on understanding customers } \\
\text { and their behaviors }\end{array}$ & $\begin{array}{l}\text { (Park \& Ramaprasad, } \\
\text { 2018) }\end{array}$ \\
\hline 4 & $\begin{array}{l}\text { Application ontology } \\
\text { (CrowdStrom) }\end{array}$ & $\begin{array}{l}\text { Sharing of non-physical resources is neglected due to } \\
\text { much focus on ontological development for sharing of } \\
\text { physical resources }\end{array}$ & (Matzner et al., 2016) \\
\hline 5 & Domain ontology & No formal ontology for knowledge management techs & (Hashemi et al., 2018) \\
\hline 6 & $\begin{array}{l}\text { Domain ontology } \\
\text { (maritime product/ } \\
\text { service-systems) }\end{array}$ & $\begin{array}{l}\text { Lack of a systematic knowledge gathering to effectively } \\
\text { evaluate the existing service solutions }\end{array}$ & $\begin{array}{l}\text { (Pagoropoulos, } \\
\text { Andersen, Kjær, Maier, } \\
\text { \& McAloone, 2014) }\end{array}$ \\
\hline 7 & Domain ontology & $\begin{array}{l}\text { A rising need to integrate heterogeneous systems for inter- } \\
\text { agency collaboration as it is becoming more widespread } \\
\text { and requires lots of information systems for support. }\end{array}$ & $\begin{array}{l}\text { (Lv, Ni, Zhou, \& Chen, } \\
\text { 2016) }\end{array}$ \\
\hline 8 & Upper ontology & $\begin{array}{l}\text { Complicated document management to automate data } \\
\text { exchange from one domain to another domain }\end{array}$ & $\begin{array}{l}\text { (Cverdelj-Fogaraši, } \\
\text { Sladić, Gostojić, } \\
\text { Segedinac, \& } \\
\text { Milosavljević, 2017) }\end{array}$ \\
\hline 9 & $\begin{array}{l}\text { Application ontology } \\
\text { (CIK-Net) }\end{array}$ & $\begin{array}{l}\text { Inadequate management of intra-organizational knowledge } \\
\text { due to ontological designs based on own business } \\
\text { environment }\end{array}$ & $\begin{array}{l}\text { (Leung, Lau, \& Tsang, } \\
\text { 2013) }\end{array}$ \\
\hline 10 & $\begin{array}{l}\text { Domain ontology } \\
\text { (business model } \\
\text { canvas for P2PSCC) }\end{array}$ & $\begin{array}{l}\text { Existence of different customer roles in peer-to-peer } \\
\text { sharing collaborative consumption (P2PSCC) is not } \\
\text { addressed; too much heterogeneity of P2PSCC services } \\
\text { lead to a quick exit from the market }\end{array}$ & $\begin{array}{l}\text { (Plenter, Fielt, Hoffen, } \\
\text { Chasin, \& Rosemann, } \\
\text { 2017) }\end{array}$ \\
\hline
\end{tabular}




\section{CHALLENGES IN ONTOLOGY DESIGN IN SHARING ECONOMY DOMAIN}

Based on the review shown in Table 1, the common ontology design challenges in the sharing economy relate to these: (i) collaborative platform management issues, (ii) tackling information overload, (iii) sustainability of the SE domain, and (iv) preference to build application ontology in SE.

\subsection{Collaborative Platform Management Issues}

The issues involving the escalating IT-enabled marketplace platforms include isolated platforms, redundancy of platform data and the short platform viability period. This creates a hassle for both merchants (providers) and users (buyers) when selecting the right platform for their needs. For example, browsing through many different platforms to compare the offers and conditions is not only time-consuming but is impractical in the long run (von Hoffen, 2017). Additionally, the redundancy of platform data often arises due to the existence of different data structures (von Hoffen et al., 2015). Plenter et al. (2017) claimed that the inability of many digital platforms to integrate efficiently cause the peer-to-peer sharing services to quickly enter and leave the digital marketplace. Hence, this suggested that ontology development in the SE domain is crucial to allow easier integration of various digital platforms (Lv et al., 2016).

\subsection{Tackling Information Overload}

In the SE domain, we have to deal with the abundance, diversity and complexity of the data derived from the knowledge of multiple agencies that are interconnected with each other (He et al., 2015). Without ontology, this condition would continue to result in losses of knowledge and information (Park \& Ramaprasad, 2018), and complexities in document management (Cverdelj-Fogaraši et al., 2017). However, designing ontology that is based on one's own business environment may also be insufficient, as it leads to inadequate management of inter-agency knowledge (Hashemi et al., 2018). Therefore, this highlighted not only the importance of having an ontology for a domain but also the need to carefully design the ontology based on a common framework.

\subsection{Sustainability of SE Domain}

In a widespread domain such as the SE, the interaction between the data often involves multiple systems (Valaski, Malucelli, \& Reinehr, 2012). Despite the versatility of ontology, the existence of multiple ontologies in a domain may lead to heterogeneity systems (Visser \& Cui, 1998). When multiple ontologies exist, the domain common language and their interactions lack consistency, resulting in difficulties for any one system to understand, share and reuse these ontologies. In addition, heterogeneity requires massive information systems support and higher resources demand, to build and maintain the ontology. Cverdelj-Fogaraši et al., (2017) also highlighted the need to govern the domain ontology so that an effortless exchange of data can be sustained.

\subsection{Preference to Build Application Ontology in SE}

Despite the adoption of ontology in the SE domain, Table 1 showed that the ontology development is very much centered to the application ontology for specific applications. Some papers discussed the domain ontology, but it is dedicated to other related domains such as knowledge management, user-design and business. Hence, this demonstrated that no common framework to assist the ontology development in the SE domain exists so far (Pagoropoulos et al., 2014). One of the possible reasons could be that the SE domain is currently at an infancy stage and is progressing. However, ontology development from a top-down approach should be considered as it is much easier and time-efficient. In addition, integrating a few applications with their own ontologies may still be doable, but integrating hundreds of applications at an application ontology level will be disastrous due to the non-existence of common knowledge. This depicted the need to opt for domain ontology development to make the knowledge in the SE domain more explicit and structured. 


\section{DISCUSSION}

This study digs deeper to further understand the behavior, characteristics and challenges in the SE domain with regards to ontology development. As every different domain faces a different set of challenges, we need to consider all the contributing factors and understand the challenges for the right ontology to be designed and developed. To further explain, we are using the "Trivago" analogy as an example. "Trivago" provides the solution to cater to the needs of hotel industries that involve inter-agency interactions (merchants who provide the hotel accommodation services and users who need the hotel accommodations, mediated by digital platforms). The existence of various digital platforms for this service is unfeasible since each platform is often standalone, making it difficult and tedious for the user to compare and get the best offers. "Trivago" understand that a common language is needed to serve as a standard that will allow integration of the various platforms and ensure systems interoperability. In short, ontology acts like the "Trivago" of the SE domain, rebuilding knowledge of systems to provide a solution to the challenges mentioned earlier. The best practice for SE ontology development is to firstly aim for simplicity through a fixed ontology during the initial phase. Then, the process may be extended to develop a more dynamic ontology for flexibility and agility, to ensure that the knowledge of this domain can be structured properly, systematically and explicitly.

\section{CONCLUSION}

The sharing economy is an emerging domain that is very knowledge-intensive and involves complex, inter-agency interactions. This paper has twofold contributions. Firstly, this paper has reviewed the state of ontology development in the SE domain and secondly, it has identified the challenges with regards to ontology design and development. There were four major challenges in building an ontology for the sharing economy, which include, collaborative platform management issues, tackling information overload, the sustainability of the SE domain and preference to build application ontology in SE. Hence, ontology development in the SE domain is important to provide a common language to allow communication between multiple players in the SE domain. Ontology is also important to manage knowledge sharing and to allow integration of various digital platforms. In SE, the development of domain ontology needs to be highly considered and focused on, rather than application ontology. This is because application ontology is mostly developed in an ad hoc or in-silo manner, suitable to fulfill the needs for a specific application. However, when integrating many existing application ontologies, issues such as heterogeneity in systems may arise. The future works of this study are to come up with the right ontology development for the SE domain through a common ontological framework.

\section{ACKNOWLEDGMENT}

This research is supported by Research University Grant (GUP), Universiti Kebangsaan Malaysia (UKM), Vot. No: GUP-2018-125. High appreciation goes to the above sponsors.

\section{REFERENCES}

Ahmad, M. N., Zakaria, N. H., \& Sedera, D. (2013). Ontology-based knowledge management for enterprise systems. In Competition, Strategy, and Modern Enterprise Information Systems (pp. 184-212). IGI Global.

Cverdelj-Fogaraši, I., Sladić, G., Gostojić, S., Segedinac, M., \& Milosavljević, B. (2017). Semantic integration of enterprise information systems using meta-metadata ontology. Information Systems and E-Business Management, 15(2), 257-304.

Gruber, T. R. (1993). A translation approach to portable ontology specifications. Knowledge Acquisition, 5(2), $199-221$.

Hashemi, P., Khadivar, A., \& Shamizanjani, M. (2018). Developing a domain ontology for knowledge management technologies. Online Information Review, 42(1), 28-44.

He, L., Ming, X., Ni, Y., Li, M., Zheng, M., \& Xu, Z. (2015). Ontology-based information integration and sharing for collaborative part and tooling development. Concurrent Engineering, 23(3), 199-212. 
Holsapple, C. W., \& Joshi, K. D. (2004). A knowledge management ontology. In Handbook on Knowledge Management 1 (pp. 89-124). Springer.

Khantong, S., \& Ahmad, M. N. (2019). An Ontology for Sharing and Managing Information in Disaster Response: In Flood Response Usage Scenarios. Journal on Data Semantics, 1-14.

Leung, N. K. Y., Lau, S. K., \& Tsang, N. (2013). An ontology-based collaborative inter-organisational knowledge management network (CIK-NET). Journal of Information \& Knowledge Management, 12(01), 1350005.

Lv, Y., Ni, Y., Zhou, H., \& Chen, L. (2016). Multi-level ontology integration model for business collaboration. The International Journal of Advanced Manufacturing Technology, 84(1-4), 445-451.

Matzner, M., Chasin, F., von Hoffen, M., Plenter, F., \& Becker, J. (2016). Designing a peer-to-peer sharing service as fuel for the development of the electric vehicle charging infrastructure. In 2016 49th Hawaii International Conference on System Sciences (HICSS) (pp. 1587-1595). IEEE.

Musen, M. A. (2002). Medical informatics: searching for underlying components. Methods of Information in Medicine, $41(01), 12-19$

Pagoropoulos, A., Andersen, J. A. B., Kjær, L. L., Maier, A., \& McAloone, T. C. (2014). Building an ontology of Product/Service-Systems: Using a maritime case study to elicit classifications and characteristics. In Working Conference on Virtual Enterprises (pp. 119-126). Springer.

Park, J., \& Ramaprasad, A. (2018). Toward ontology of designer-user interaction in the design process: a knowledge management foundation. Journal of Knowledge Management, 22(1), 201-218.

Plenter, F., Fielt, E., Hoffen, M., Chasin, F., \& Rosemann, M. (2017). Repainting the business model canvas for peer-to-peer sharing and collaborative consumption.

Sutherland, W., \& Jarrahi, M. H. (2018). The sharing economy and digital platforms: A review and research agenda. International Journal of Information Management, 43, 328-341.

Valaski, J., Malucelli, A., \& Reinehr, S. (2012). Ontologies application in organizational learning: A literature review. Expert Systems with Applications, 39(8), 7555-7561.

Visser, P. R. S., \& Cui, Z. (1998). On accepting heterogeneous ontologies in distributed architectures. In Proceedings of the ECAI98 workshop on applications of ontologies and problem-solving methods.

von Hoffen, M. (2017). The Sharing Economy Meets the Semantic Web: An Ontology for the Matchmaking of Peers. In 2017 IEEE 11th International Conference on Semantic Computing (ICSC) (pp. 212-219). IEEE.

von Hoffen, M., Matzner, M., \& Chasin, F. (2015). Designing an Ontology-based Web Directory for the Discovery of Sharing and Collaborative Consumption Platforms. In 2015 IEEE 17th Conference on Business Informatics (Vol. 1, pp. 108-115). IEEE. 